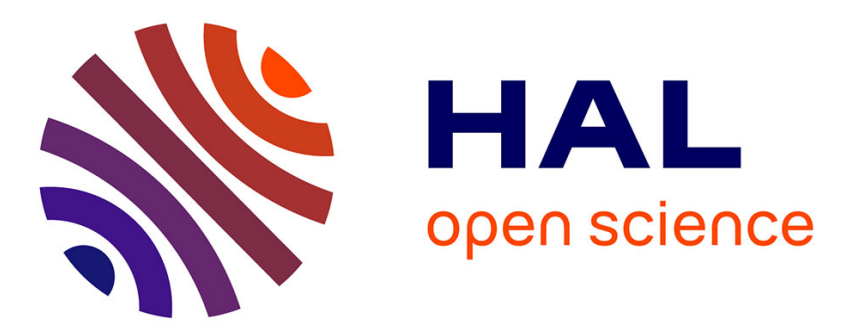

\title{
Weighing synthetic polymers of ultra-high molar mass and polymeric nanomaterials: What can we learn from charge detection mass spectrometry?
}

Rodolphe Antoine

\section{- To cite this version:}

Rodolphe Antoine. Weighing synthetic polymers of ultra-high molar mass and polymeric nanomaterials: What can we learn from charge detection mass spectrometry?. Rapid Communications in Mass Spectrometry, 2020, 34 (S2), pp.e8539. 10.1002/rcm.8539 . hal-02480782

\section{HAL Id: hal-02480782 \\ https://hal.science/hal-02480782}

Submitted on 31 Oct 2020

HAL is a multi-disciplinary open access archive for the deposit and dissemination of scientific research documents, whether they are published or not. The documents may come from teaching and research institutions in France or abroad, or from public or private research centers.
L'archive ouverte pluridisciplinaire HAL, est destinée au dépôt et à la diffusion de documents scientifiques de niveau recherche, publiés ou non, émanant des établissements d'enseignement et de recherche français ou étrangers, des laboratoires publics ou privés. 


\title{
Weighing synthetic polymers of ultra-high molar mass and polymeric nanomaterials: What can we learn from charge detection mass spectrometry?
}

\author{
Rodolphe Antoine
}

Univ Lyon, Université Claude Bernard Lyon 1, CNRS, Institut Lumière Matière, UMR 5306, F-69622 Lyon, France

*Corresponding Author. Email: rodolphe.antoine@univ-lyon1.fr

Special Issue on Synthetic Polymers in Rapid Communications in Mass Spectrometry

ABSTRACT: Advances in soft ionization techniques for mass spectrometry of polymeric materials make it possible to determine the mass of intact molecular ions exceeding megadalton. Interfacing mass spectrometry with separation and fragmentation methods has additionally led to impressive advances in the ability to structurally characterize polymers. Even if the gap to the megadalton range has been bridged by MS for polymers standards, the MS-based analysis for more complex polymeric materials is still challenging. Charge detection mass spectrometry (CDMS) is a single molecule method where the mass and the charge of each ion is directly determined from individual measurements. The entire molecular mass distribution of a polymer sample can be thus accurately measured. In this perspective paper, I will also describe how molecular weight distribution as well as charge distribution can provide new insights into the structural and compositional studies of synthetic polymers and polymeric nanomaterials in the megadalton to gigadalton range of molecular weight. The recent multidimensional CDMS studies involving couplings with separation and dissociation techniques will be presented. And finally, an outlook for the future avenues of the CDMS technique in the field of synthetic polymers of ultra-high molar mass and polymeric nanomaterials will be provided. 


\section{Introduction}

Synthetic polymers are unique materials consisting of a statistical distribution of chains of varying lengths. Polymerization reactions produce a large palette of molecular weight (MW) distributions and morphologies. Synthetic polymers exist in a wide variety of molecular weights (from few hundreds of dalton to several tens of gigadalton) as well as under diverse shapes (linear, branched, dendritic, 3-D polymeric self-assembly architectures...) and therefore are difficult to characterize. ${ }^{[1]}$ There are numerous techniques employed for the analysis and characterization of synthetic polymers. A number of them are spectroscopic-based techniques ${ }^{[2]}$ used in many areas of chemistry (e.g., nuclear magnetic resonance (NMR), infrared spectroscopy (IR) and ultraviolet/visible (UV/vis), mass spectrometry (MS)) while some are applied mostly in the area of polymer chemistry (e.g., membrane osmometry, light scattering, gel permeation chromatography, intrinsic viscosity). ${ }^{[3]}$

Mass spectrometry (MS) is a powerful analytical technique due to its high sensitivity, low sample consumption, and speed of analysis. In order to determine the composition and the identity of an analyte, this analytical technique measures the mass-to-charge ratio $(\mathrm{m} / \mathrm{z})$ of gas-phase ions generated from the analyte. NMR, IR, and UV/vis spectroscopies have a long history in polymer analysis, while many polymer chemists prior to the mid-1990s had a rather skeptical opinion of mass spectrometry for polymer analysis. ${ }^{[4]}$ This rather dubious reputation for mass spectrometry was due to the fact that the polymer needs to be vaporized/ionized, remaining intact prior to mass analysis. The use of mass spectrometry for polymer analysis took on a new dimension in the early 2000s, thanks to the advent of new ionization techniques. Electrospray ionization (ESI) ${ }^{[5]}$ and matrix assisted laser desorption/ionization (MALDI) ${ }^{[6,7]}$ are "soft" ionization techniques that have gained prominence in the characterization of synthetic polymers, because they can form intact gas-phase ions from such molecules. Furthermore, because the gas-phase ions are separated according to their mass-to-charge ratio $(\mathrm{m} / \mathrm{z})$, MS coupled to "soft" ionization techniques allows for fractionation of mass and thus for an exhaustive characterization of the distribution of molecular weights, a particularly useful feature for synthetic polymers. As a result, these two techniques have been used widely in structural and compositional studies of synthetic polymers in the kilodalton range of molecular weight. ${ }^{[8-14]}$

Advances in polymer synthesis have led to the production of more and more complex polymeric materials, e.g. complex mixtures of oligomers, polymer self-assembly, ultra-high molecular weight polymers, ... for which molecular weight characterization based on some indirect property, such as the scattering of light or the binding affinity to a stationary phase, are often tricky or even unsolvable. There have been notable developments in MALDI as well as in ESI towards extending 
mass range required for analyzing such complex polymeric materials. Using ESI-Fourier transform mass spectrometry, McLafferty and co-workers analyzed 4.5, 14, and 23 kDa poly(ethylene glycol) (PEG) samples. ${ }^{[15]}$ With mass resolving power in the range of $10^{4}-10^{5}$, fully resolved isotopic peaks of the PEG oligomers were provided. However, overlapping charge distributions complicate mass determination and hence composition assignment. And, for the interpretation of the complex ESI/FTMS spectra of polymers, a combination of deconvolution algorithms modified to minimize artifact peaks while retaining accurate abundance information was required. Nevertheless, examples of high molecular weight analysis of synthetic polymers in the megadalton range by ESI-mass spectrometry are still uncommon to date. Aksenov and Bier proposed a superconducting tunnel junction (STJ) cryodetector in combination with MALDI-TOF mass spectrometry towards the analysis of polystyrene and polystyrene aggregates into the megadalton mass range. ${ }^{[16]}$ Other examples of MALDI-TOF mass spectrometry in the megadalton range have been reported with polystyrene standards or even with highest generation dendrimers. ${ }^{[17-21]}$

Even if the gap to the megadalton range has been bridged by MS for polymers standards with low dispersity and high purity, the MS-based analysis for more complex polymeric materials is still challenging, partly due to the fact that their polymeric components cannot be distinguished by $\mathrm{m} / \mathrm{z}$ measurements alone. Such problems can be addressed by interfacing MS with a separation method either before ionization (liquid chromatography mass spectrometry) or after ionization (ion-mobility mass spectrometry). The development of suitable hyphenated separation approaches for efficient reduction of complexity has led to multidimensional mass spectrometry, and has been recently reviewed by Chrys Wesdemiotis. ${ }^{[10]}$ However, for synthetic polymers the upper mass limit in the multidimensional MS studies is about $15 \mathrm{kDa}$. Thus, between the current limitations of mass spectrometry to characterize synthetic polymers of ultra-high molecular weight and polymeric nanomaterials by only measuring their $\mathrm{m} / \mathrm{z}$ values and the emergence of analytical techniques mostly developed in the area of polymer chemistry for "weighing" or "sizing" polymer nanomaterials, is there still a room for mass spectrometry?

One way to overcome the limitations described above is to directly determine the mass or more precisely the $m / z$ and the charge $z$ of each ion, instead of only measuring $m / z$ values of a collection of ions. This multidimensional MS strategy (2-D : $\mathrm{m} / \mathrm{z}$ and $z$ ) at the single ion level can be fulfilled by the charge detection mass spectrometry (CDMS) technique. CDMS in the single pass mode (single passCDMS) ${ }^{[22]}$ is based on a very simple concept: an ion passing through a conducting cylinder will induce an image charge (that is proportional to its charge). The velocity of the individual incoming ion is obtained from the tube length and from the duration of the image charge signal corresponding to 
the ion entering and exiting the tube (time-of-flight TOF). The $m / z$ of the ion is determined from its energy and velocity. The mass of each ion is obtained from the independent charge $z$ and $m / z$ measurements. CDMS was developed in 1960 by Shelton for measuring the masses of charged, micron-sized iron particles before they impact craters on surfaces. ${ }^{[23]}$ In 1995 , Fuerstenau and Benner ${ }^{[22]}$ coupled CDMS to electrospray ionization and really pushed the envelope of this technique in analyzing macromolecules in the MDa range and opened the door to the future studies of biological species and nanoparticles. In the recent years, CDMS has undergone a revival, thanks to impressive technical developments proposed by the group of Martin Jarrold, ${ }^{[24,25]}$ improving the resolution enabling the determination of stoichiometry of assemblies, ${ }^{[26]}$ protein complexes, ${ }^{[27-35]}$ viruses, ${ }^{[29,36,37]}$ and virus assembly intermediates. ${ }^{[28,30-35,38-40]}$ From our side, we were interested in pushing the limit of CDMS and its couplings with separative ${ }^{[41]}$ and dissociation techniques ${ }^{[42-47]}$ for the determination of the mass and charge distribution of very heterogeneous samples such as polymers, ${ }^{[48-54]}$ nanoparticles, ${ }^{[55,56]}$ and amyloid fibrils. ${ }^{[57-59]}$

After beginning with the basic principles of electrospray ionization charge detection mass spectrometry, this perspective paper describes how molecular weight distribution as well as charge distribution can provide new insights into the structural and compositional studies of synthetic polymers and polymeric nanomaterials in the megadalton to gigadalton range of molecular weight. Then, the recent multidimensional CDMS studies involving couplings with separation techniques and dissociation techniques will be presented. And finally, an outlook for the future avenues of the CDMS technique in the field of synthetic polymers of ultra-high molar mass and polymeric nanomaterials will be provided.

\section{Electrospray ionization single pass-CDMS}

The mass spectrometry device developed for weighing polymers of ultra-high molar mass and polymeric nanomaterials combines an electrospray ionization source and an image charge detector (see Figure 1a and 1b). The design of the electrospray ion source interface used in our group is based on that of Whitehouse and Fenn. ${ }^{[5,60]}$ An ionic train device is used for focusing electrosprayed ions in an intermediate vacuum regime (between few torr to few $10^{-5}$ torr), as shown schematically in Figure 1a). Electrospray ionization (ESI) involves the release of ions achieved by spraying the sample using an electrical field so that charged droplets are formed. We measured the charge and mass of individual electrosprayed water droplets by our image charge detection device transmitted through a capillary interface (see figure 1c), confirming the capability of electrospray source to produce highly charged droplets (in agreement with previous published by Jarrold and coworkers). ${ }^{[61-63]}$ Since 
electrosprayed water droplets are highly charged, the resulting electrosprayed ions of analytes embedded in droplets can be also highly charged. ${ }^{[64]}$ Since image charge detection is based on single ion charge measurements, the coupling between electrospray ionization source and image chargedetection represents a perfect marriage for weighing heavy things. The charge of electrosprayed ions depends on their size as well as their shape. For spherical-like polymer particles, the charging will be mainly driven by the charging of hosting water droplets and limited by their Rayleigh limit (but also of functional groups on the surface of the particle proned to be charged). ${ }^{[50]}$ For linear-like (or chainlike) polymer particles, the charging capacity will be driven by the balance between the affinity of cations for the polymer binding sites and the electrostatic repulsive potential energy. ${ }^{[48]}$ Thus the overall charge of electrospray ions of polymers of ultra-high molar mass and polymeric nanomaterials can range from few hundreds to several thousands of elementary charges (as illustrated in figure $1 \mathrm{~d}$ ) for PEO polymer ions (average MW 7 MDa). Electrospray conditions to produce a high current of electroprayed ions can be obtained thanks to a subtle trade-off between different interdependent source parameters. Our optimal experimental conditions include a nitrogen drying gas injected within the needle and a counterflow of heated nitrogen drying gas $\left(200^{\circ} \mathrm{C}\right)$ between the entrance electrode and the glass capillary and collision-induced desolvation. Hence, the flow rate, the nitrogen pressure in the electrospray source and the distance between the needle and the end-cap should be chosen carefully in order to enhance desolvation for producing enhanced ions from polymers of ultra-high molar mass and polymeric nanomaterials. The ionic train device permitting to transfer ions transmitted through the capillary interface of ESI source to the charge detection device, is thus an essential part. In our group, we followed the design proposed by Benner and coworkers, ${ }^{[22]}$ and we use multipole RF ion guides. The conditions for a particle of a certain mass-to-charge-ratio and energy to pass the multipole can be estimated using the adiabatic approximation, which yields the minimum and maximum transmitted mass-to-charge-ratios as formalized by Gerlich and coworkers. ${ }^{[65]}$ The ion guides used in our group operate at Rf frequency of $\sim 5 \mathrm{MHz}$ with typically $\sim 500$ $\checkmark$ peak-to-peak voltage amplitude. These conditions permit to efficiently transmit ions in the $10^{2}-$ $10^{5} \mathrm{~m} / \mathrm{z}$ range (see fig. 1e). Also, ion funnels, where a DC gradient draws the ions towards the exit of the funnel while rf (around $600 \mathrm{kHz}$ ) provides the pseudopotential that focuses the ions, have been used by Jarrold and coworkers. ${ }^{[66]}$ Conventional ion guides or funnels have little effect to compensate the large amount of energy picked up by high-mass ions from the gas flow through the capillary of electrospray sources. Alternatively, Jarrold and coworkers proposed a hybrid device -the FUNPETcombining a virtual jet disruptor and an ion funnel-ion carpet interface. ${ }^{[67]}$ For heavier ions $(\mathrm{m} / \mathrm{z}>$ $10^{5}$ ), RF ion guides are not anymore efficient. For this purpose, Continetti and coworkers proposed 
an innovative guiding device based on an aerodynamic lens design to efficiently transmit over $95 \%$ of particles in the range of $75-1200 \mathrm{~nm}^{\text {[68] }}$

The image charge detection has been widely used in Fourier transform ion cyclotron resonance mass spectrometry (FTICR) ${ }^{[69-71]}$ and Orbitrap ${ }^{\text {TM }} .^{[72]}$ While FT-MS instruments use ion packets, CDMS instruments have been developed to enhance the detection sensitivity and the resolution of charge evaluation for a single heavy ion with multiple charges. Single ions are introduced in the charge detection devices after ion guides. Of note, the counting rate for typical CDMS experiments is typically $10-100 \mathrm{~Hz}$, meaning that one ion is detected every $0.01-0.1 \mathrm{~s}$. The travel time through the charge detector tube is 10-100 $\mu \mathrm{s}$. Thus the probability that two or more ions enters simultaneously in the detector is extremely weak, and only single ion detection occurs. Thus we manage to control single ion detection in the charge detection tube, by limiting the counting rate to frequency lower than $100 \mathrm{~Hz}$. Focusing ions along the axis of the charge detection device with Einzel-type lenses permits to increase detection efficiency.

a)

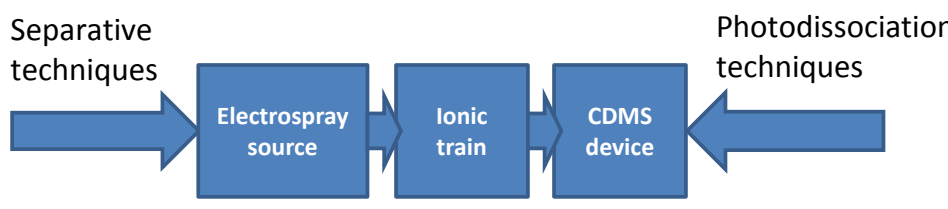

b) Single-pass CDMS

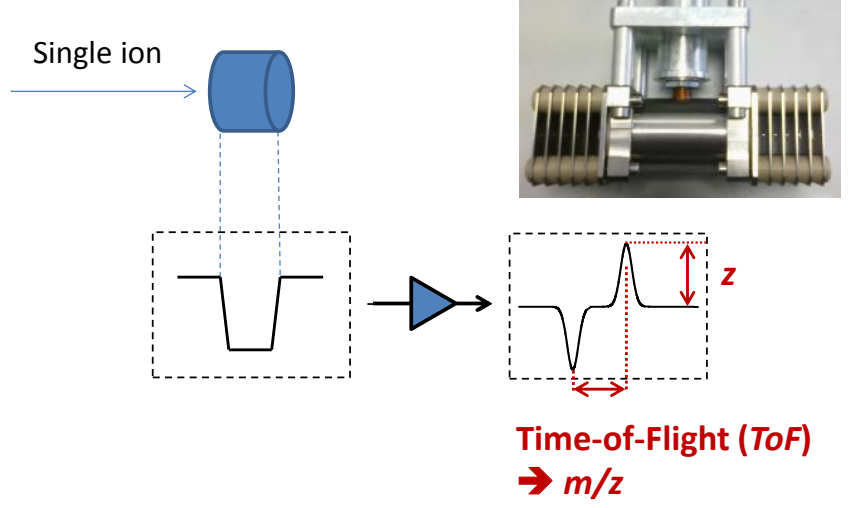

c)

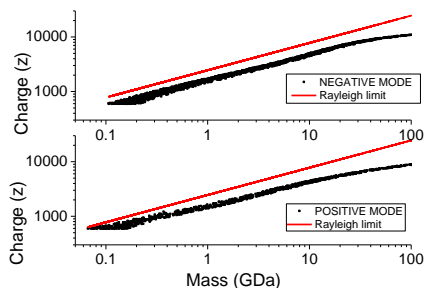

d)

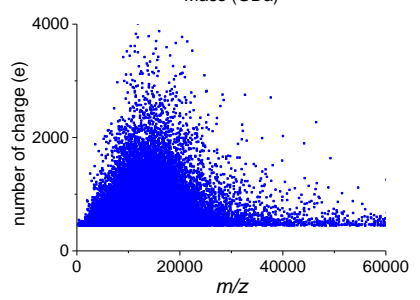

e)

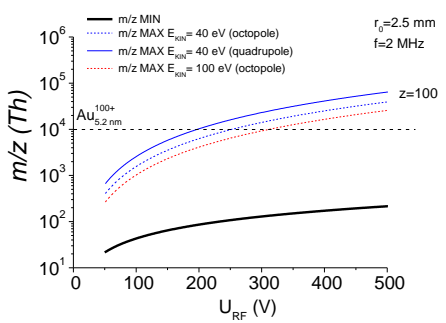

Figure 1 : a) Schematic view of a single pass charge detection set-up, comprising an ionization source, an ionic train and a charge detection tube. b) Schematics principles of single pass CDMS; the charge $z$ of single ions is determined by the amplitude measured by image charge through the tube and the $\mathrm{m} / \mathrm{z}$ is determined from the TOF through the tube (and the ion's kinetic energy). Inset : photograph of charge detection device. c) Mass-charge plot for residual electrosprayed water droplets in positive and negative modes of ionization. The solid red curve gives the predicted charge versus

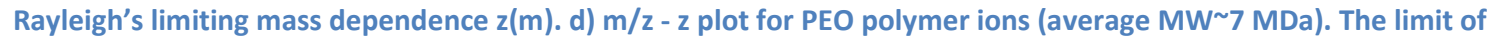
detection in charge is evidenced and is about $400 \mathrm{e}$ in this case. e) Minimum ( $\mathrm{m} / \mathrm{z} \mathrm{MIN}$ ) and maximum (m/z MAX) 
transmitted mass to- charge-ratio for multipole devices with an ion energy of $40 \mathrm{eV}(100 \mathrm{eV})$ per charge. The conditions for a particle of a certain mass-to-charge-ratio and energy to pass the multipole can be estimated using the adiabatic approximation, which yields the minimum and maximum transmitted mass-to-charge-ratios.

The charge detection device (CDD), is shown in inset of Fig. 1b. The image charge is collected by a "pick-up" tube (high impedance) and is transmitted to a JFET transistor (Junction Field Effect Transistor). This JFET associated with a preamplifier, converts the current induced voltage. In order to lower the link impedances, the JFET transistor, the preamplifier and the first amplification stage are mounted on an integrated printed circuit inside the holding tube (perpendicular to CDD, see photograph in Fig. 1b). When a single ion travels through the tube, the charge induced on the outsides of the conducting tube is detected by the charge sensitive preamplifier. Additionally, the tube diameter must be large enough to intersect and capture a measurable portion of the ion beam. Typically the tube diameter is between about $4 \mathrm{~mm}$ and about $8 \mathrm{~mm}$ and the tube length is between about $4 \mathrm{~mm}$ and about $160 \mathrm{~mm}$. The tube used in our group is $3.75 \mathrm{~cm}$ long and had a $6 \mathrm{~mm}$ internal diameter. The resulting trapezoidal-like signal from the preamplifier is then processed with a differential amplifier and filters yielding a pulse when an ion enters the tube and a pulse of the opposite polarity when it exits (see fig. 1b). Green's reciprocity Theorem states that the ratio of the potential at a point $P$ in space, relative to the ring potential, is equal to the negative of the ratio of charge imaged on the ring by a charge present at $\mathrm{P}^{\left[{ }^{[7]}\right.}$ In essence, this means that the image charge detector has a spatially dependent response function. Thus the rise and fall times depend on the ion velocity and the diameter of the tube. The ion charge is usually determined from the pulse amplitudes, in which case the shaping time constants must be much longer than the rise and fall times of the induced charge (case of synthetic polymers of ultra-high molar mass). For shaping time constants in the order or shorter than the rise and fall times of the induced charge, the charge must be determined from the pulse area (case of heavier polymeric nanomaterials). In addition, the charge measurement is usually calibrated. A test capacitor allows a known amount of charge to be pulsed onto the pick-up tube for calibration purposes. The test pulses are generated with a shapingpulse generator so that the time dependent signal response can also be determined. In single-pass CDMS, the $m / z$ is extracted from the flight time TOF $=\Delta t$ through the tube, which is obtained from the entrance and exit pulses of the ion. The ion velocity $v_{m}$ is $v_{m}=\frac{L}{\Delta t}$ and $\frac{m}{z}=\frac{2 e V}{v_{m}^{2}-v_{g}^{2}}$, where $L$ is the length of the detector tube, $m$ is the mass, $z$ is the number of charges, $V$ the electrostatic acceleration voltage. In our system, a correction is needed to take into account the initial kinetic energy imparted to the ion by the free jet expansion of the gas prior to acceleration by the electric field. vg, is the ion velocity due to the free gas expansion (or due to the particles for sub-GDa 
polymeric nanomaterials). It is determined by grounding all electrostatic lenses and timing the passage of the ion through the detector. This allows us to internally calibrate our charge detection mass spectrometer. However, this simple method does not take into account the distribution of ion energies from the gas expansion, which may cause some artefacts. To further improve the calibration, we used polystyrene microspheres (50, 70, 100, 150 and $200 \mathrm{~nm}$ diameter) as external calibrants. ${ }^{[49]}$ Such polystyrene microspheres cover the mass range of polymeric nanomaterials investigated in our work, have low size dispersion and have been found to be softly and efficiently transferred in the gas phase by ESI. ${ }^{[74,75]}$ The average mass values obtained from mass distribution for the polystyrene microsphere ions measured by CD-MS using the internal calibration were plotted against their calculated mass (the average volumes or of polystyrenes extracted from transmission electron microscopy or disc centrifuge measurements were converted in molecular mass assuming perfectly spherical nanoobjects and a homogeneous density of 1.05). A linear fit through the measured mass values was used for the external calibration.

In charge detection mass spectrometry, the mass $m$ is calculated using :

$\mathrm{m}=\frac{2 \mathrm{zeV}}{\mathrm{v}_{\mathrm{m}}^{2}-\mathrm{v}_{\mathrm{g}}^{2}}$

An error analysis of Eq. (1) yields the simple result that the instrument resolution,

$\mathrm{R}=\frac{\mathrm{m}}{\Delta \mathrm{m}}$

is related to uncertainties in charge and flight time in the following manner:

$$
\mathrm{R}_{\mathrm{z}}=\frac{\mathrm{z}}{\Delta \mathrm{z}}
$$

$$
\text { and } \mathrm{R}_{\mathrm{t}}=\frac{\mathrm{t}}{2 \Delta \mathrm{t}}\left(1-\frac{\mathrm{v}_{\mathrm{g}}^{2}}{\mathrm{v}_{\mathrm{m}}^{2}}\right)^{1 / 2}
$$

where $\mathrm{Rz}$ and $\mathrm{Rt}$ are the components of the overall resolution associated with charge and time measurement respectively. The overall resolution is given by 
In the sub-GDa molecular weight range explored for polymeric nanomaterials, most amplified pulses induced by passing micellar ions have a $<80 \mu$ s flight-time and average charge amplitude of 1000 2000 electrons. $\frac{v_{\mathrm{g}}^{2}}{v_{\mathrm{m}}^{2}}$ is 0.6-0.7. The r.m.s. noise level on the detector is typically $\sim 100$ electrons. The associated timing jitter caused by the noise in the charge measurement is $\sim 500 \mathrm{~ns}$. Thus the resolution associated with charge is $10-20$ and the resolution associated with time measurement is $\sim 100-200$. This leads to an overall resolution mainly driven by the charge precision which is usually lower than 20. If mass accuracy is not the key parameter for mass measurement, single-pass CDMS is then a useful MS technique. In particular for polymer chemistry, mass distribution of polymers of ultra-high molar mass and polymeric nanomaterials is often more important than precise mass measurements. Furthermore, $>1000$ ions per second can be analyzed with single-pass CDMS, making it the fastest CDMS technique. Typical mass spectra contain $z, m / z$ measurements of 5000-1000 single ions (see Fig. 1d) and can be recorded in less than one minute. Averaging TOF and $z$ information by using linear arrays of image charge detectors or placing the image charge detector in an electrostatic trap are examples to improve resolution in CDMS technique. ${ }^{[24,25,42]}{ }^{[76,77]}$ But such improved CDMS techniques are often time-consuming to record and process data (and will not be discussed in this perspective article).

The single-pass CDMS is imprecise due to the fact that the charge uncertainty of single-pass CDMS is fundamentally limited by detector noise. Since an ion cannot be detected if its signal rising is below the noise, the current limit of detection is $\sim 150$ e. The charges on electrosprayed ions are correlated with their mass (or their size). ${ }^{[78]}$ For linear-like synthetic polymers, the charging capacity will be driven by the balance between the affinity of cations for the polymer binding sites and the electrostatic repulsive potential energy, so ions as small as few hundred of $\mathrm{kDa}$ are prone to be detected. On the other hand, for spherical-like polymer particles, the charging will be mainly limited by their Rayleigh limit. The charge of spherical nanoparticles electrosprayed from water solution are usually as charge as 0.6-0.7 the Rayleigh's limiting charge. ${ }^{[50,61]}$ In term of size, for spherical particles, our current set-up is thus limited to nanoparticles with diameters higher than $\sim 30 \mathrm{~nm}$.

\section{Molecular weight distribution of synthetic polymers and polymeric nanomaterials}


Ideally, mass spectrometry provides a quantitative measure of the molecular weight distribution of the polymer samples. Since simultaneous $\mathrm{z}$ and $\mathrm{m} / \mathrm{z}$ measurements of several thousands single ions can be recorded in less than one minute, for each ion, the mass is deduced from its $\mathrm{m} / \mathrm{z}$ and $\mathrm{z}$ values. Consequently single-pass CDMS represent thus an ideal technique to give a direct measurement of the molar mass and the molar mass distribution of nanoobjects in the megadalton to the gigadalton range, free of model assumptions and with a short response time. However, the measurement efficiency for a given polymeric species in a distribution depends on a number of factors, including the efficiency of ionization, ion transmission and finally detection. Importantly, the ability to measure an accurate mass distribution for polymers or nanoparticles depends on there not being any sort of systematic mass discrimination either in the ionization process, the transport of the ions into vacuum, and the detection process. Electrospray ionization (ESI) is great. It can be used to gently transfer just about anything into the gas phase in an ionized state. The detection process is based on image charge detection and is not supposed to induce any sort of systematic mass discrimination. However, the transport of the ions into vacuum using multipole RF devices may present such mass discrimination as discussed and displayed in Figure 1e.

Using electrospray ionization technique, it is necessary to remove efficiently any solvent molecules attached to the electrospray polymer ions for accurate measurements of the molecular mass of the sample. Thus, usually, a strong countercurrent flow of heated gas for warming ions helps for efficient desolvation before the ions enter the vacuum of the mass spectrometer. $A$ heated glass capillary along with collision-induced desolvation in the differentially pumped interface regions were also implemented in the experimental set-up proposed by Benner and co-workers for weighing MDa DNA macroions. ${ }^{[79-81]} \mathrm{A}$ slightly lower and more reproducible mass value was always obtained with the heater on. In the absence of a heated capillary, it necessary to use, in addition to nitrogen drying gas injected within the needle, a strong countercurrent flow (typically 6-9 L/min) of a heated gas to achieve complete desolvation. 

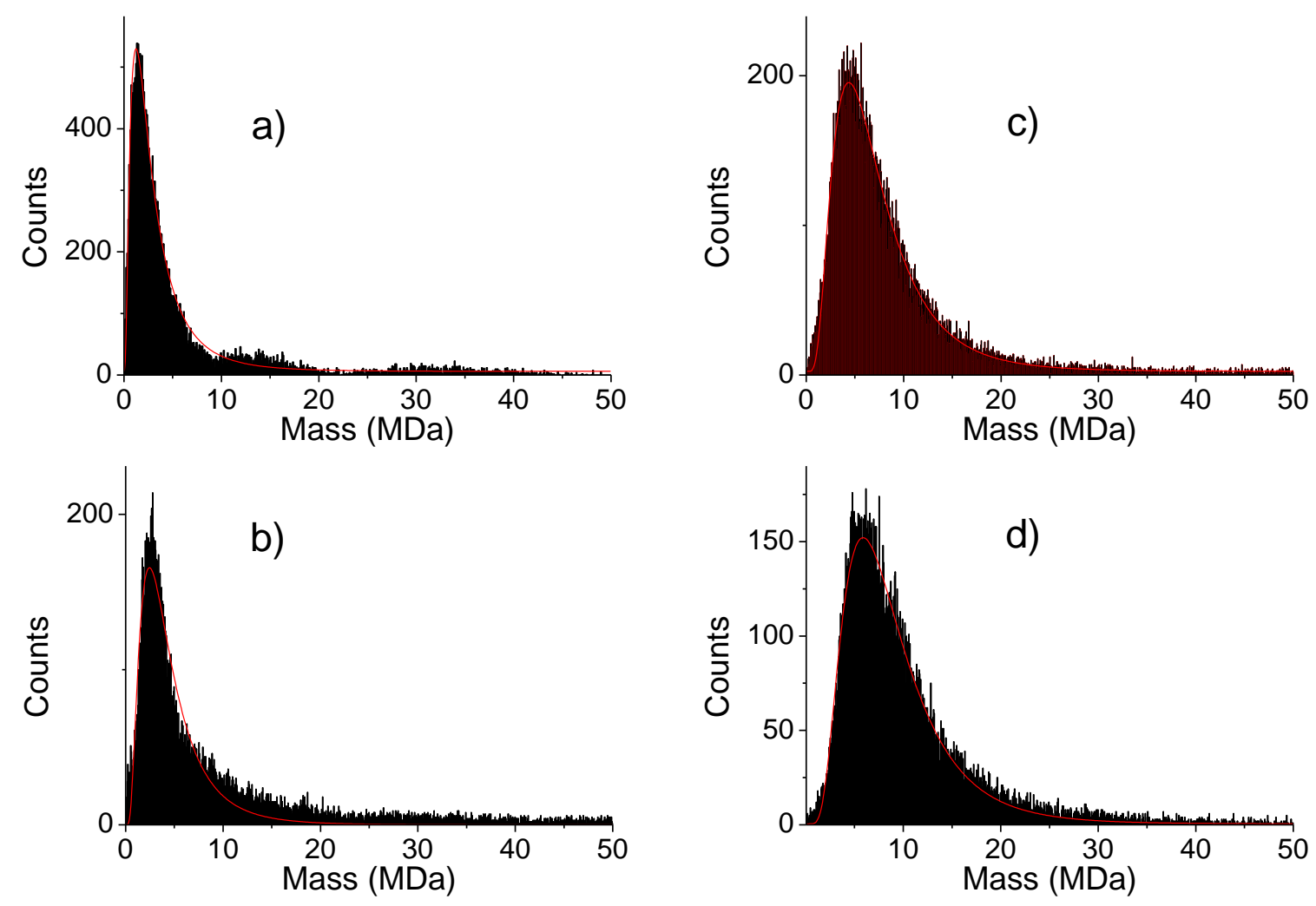

Figure 2 : Histogram mass spectra of (a) $1 \mathrm{MDa}$, (b) $2 \mathrm{MDa}$, (c) $4 \mathrm{MDa}$, and (d) $7 \mathrm{MDa}$ poly(ethylene oxide) samples. The shape of the molecular weight distribution is fitted by a lognormal distribution. The fits lead to polydespersity index $I_{p}$ equal to (a) 1.4, (b) 1.6, (c) 1.5 and (d) 2.1. (adapted from ref. 48).

The distribution of mass for these ions is usually histogrammed from mass measurements of several thousands single ions. Fig. 2 displays the histogram mass spectra of $1 \mathrm{MDa}, 2 \mathrm{MDa}, 4 \mathrm{MDa}$, and 7 MDa poly(ethylene oxide) samples. ${ }^{[48]}$ The molecular mass distributions of the polymers present maxima at 1.4, 2.7, 4.4 and 6.2 MDa. The shape of the molecular weight distribution (MWD) can be fitted by a lognormal (LN) distribution (see Fig. 2). This is a general trend that we observed for most of mass distributions recorded for synthetic polymers of ultra-high molar mass and polymeric nanomaterials. The lognormal MWD is expected to be a good fit of the experimental distribution for synthetic polymers. In general, any experimental molecular weight distribution can be approximated by some well-defined continuous statistical distribution function. LN distribution can be defined as: ${ }^{[82]}$

$$
P(M)=\frac{1}{\sqrt{2 \pi} M \sigma} \exp \left[-\frac{1}{2}\left(\frac{\ln \left(M / m_{0}\right)}{\sigma}\right)^{2}\right]
$$

where the parameter $\mathbf{m}_{0}$ characterizes the location of the distribution and $\sigma$ its breadth. The ratio between the weight average $\left(\overline{\mathbf{M}}_{\mathbf{w}}\right)$ and number average molecular weight $\left(\overline{\mathbf{M}}_{\mathbf{n}}\right)$, known as the 
dispersity, $\boxminus$ ) is commonly used to characterize the breadth of molecular weight distributions for polydisperse systems. It is interesting to note that the dispersity is only dependent on the breadth characteristic parameter s of the log-normal distribution:

$$
\bigoplus=\frac{\overline{\mathbf{M}}_{\mathrm{w}}}{\overline{\mathbf{M}}_{\mathrm{n}}}=\exp \left(\sigma^{2}\right)
$$

Our group also used a single-pass CDMS to determine the mass of polymeric nanoparticles, comprised of latex nanoparticles, ${ }^{[51]}$ coordination polymeric supramolecular self-assembly, ${ }^{[26]}$ selfassembled amphiphilic block copolymers, ${ }^{[49,50]}$ silica/polymer heterodimers and dimpled polymer particles ${ }^{[52,53]}$ and diblock copolymer vesicles. ${ }^{[54]}$ The mass distributions of the preparations of polymeric nanoparticles were monomodal and relatively broad, due to the variability in the number of polymers in the particles. The ability to characterize mass distributions and dispersity of synthetic polymer particles represent a breakthrough in macro-polymer science, and the supramolecular chemistry community would be well served by utilizing this analytical discipline in a more intensive manner for molecular weight characterization of a large panel of nano-objects.

\section{The added value of charge measurements}

In addition to mass measurements, CDMS provides charge distributions, which permits to investigate the charging of large electrosprayed ions as the function of their size. Our group thoroughly explored the charging capacity of various particles in order to use the charge measurement as an indirect probe of conformation (for flexible polymers) ${ }^{[48]}$ or morphology (for rigid polymeric nanomaterials). ${ }^{[53]}$ Indeed, the charging capacity will generally depend on the accessibility of the ionizable groups on the surface of the nano-object and thus should reflect the surface area (which is sensitive to the shape of the nano-object).

As a preliminary study, the charging capacity of electrosprayed PEOs with average molecular weights ranging from 1 to $7 \mathrm{MDa}$ was explored by single pass-CDMS. A relatively low number of charges were observed, compared with the prediction of a simple electrostatic model. ${ }^{[48]}$ This was attributed to the fact that MDa PEO chains (within droplets) stay partially folded when being electrosprayed, thus preventing access to all the sites that could theoretically have been cationized.

Clearly, this study on PEOs raised an interesting question about the relation between charging of macromolecules in the solution and gas phases. Single pass-CDMS has been found to be a versatile MS-based technique to thoroughly explore the charging capacity of polymeric nanoobjects. ${ }^{[50]}$ It has been shown that the charging of the nanoparticles, weighing between 500 and 2000 MDa, in water by electrospray ionization is $\sim 60 \%$ of the Rayleigh's limiting charge of charged water droplet of the same dimensions. Then, our group has shown that charging of micellar nanoparticles could be 
increased by the addition of supercharging agents (piperdine). ${ }^{[50]}$ Similar charge distributions are observed in positive and negative mode of ionization. Specifically, the charging of negatively and positively charged polymeric nanoparticles were measured and compared to results obtained from solution-based zeta potential measurements (for which an average charge on the particle in solution can be extracted). ${ }^{[51]}$ The effective charges extracted from the measured zeta-potential of nanoparticles in solution were partially correlated with the average values of charge of nanoparticles in the gas phase. However, a more thorough study with colloidal objects, for which molecular weight are the same and surface charging would be changed using different ligand-coated NPs, is required to enable the universality of this correlation.

Finally, we aimed at using the charging measurement obtained by CDMS analysis as a tool for the morphological characterization of polymeric nanoparticles. Figure 3a) displays 3D mass-charge map of electrosprayed vesicles together with the predicted limiting curve for water droplets at $60 \%$ of the Rayleigh's limiting charge as a function of the mass. ${ }^{[54]}$ We have been able to estimate an equivalent diameter for vesicles by comparing their average charge to the corresponding charge of a water droplet at $60 \%$ of the Rayleigh's limiting charge. The average number of charge is 1838 . This charge would correspond to a water droplet with a diameter of $170.1 \mathrm{~nm}$ as shown in Figure 3a). We postulated that the diameter of vesicles is given by this equivalent water droplet diameter. With this diameter, the corresponding density of vesicles would be 0.66 which is much lower than the density of polymers ( 1.25) but in agreement with the one extracted from SAXS and indicates that vesicles are preserved in the gas phase (while perhaps slightly contracted leading to a higher density than the one extracted from SAXS measurements). Furthermore, Comparison of CDMS and SAXS data also shows good agreement for vesicle membrane thickness measurement (see Fig. 3b), though the vesicle membrane thicknesses calculated from CDMS information are lower than those reported by both SAXS and DLS, probably due to the dehydration that occurs in vacuum. ${ }^{[54]}$ 

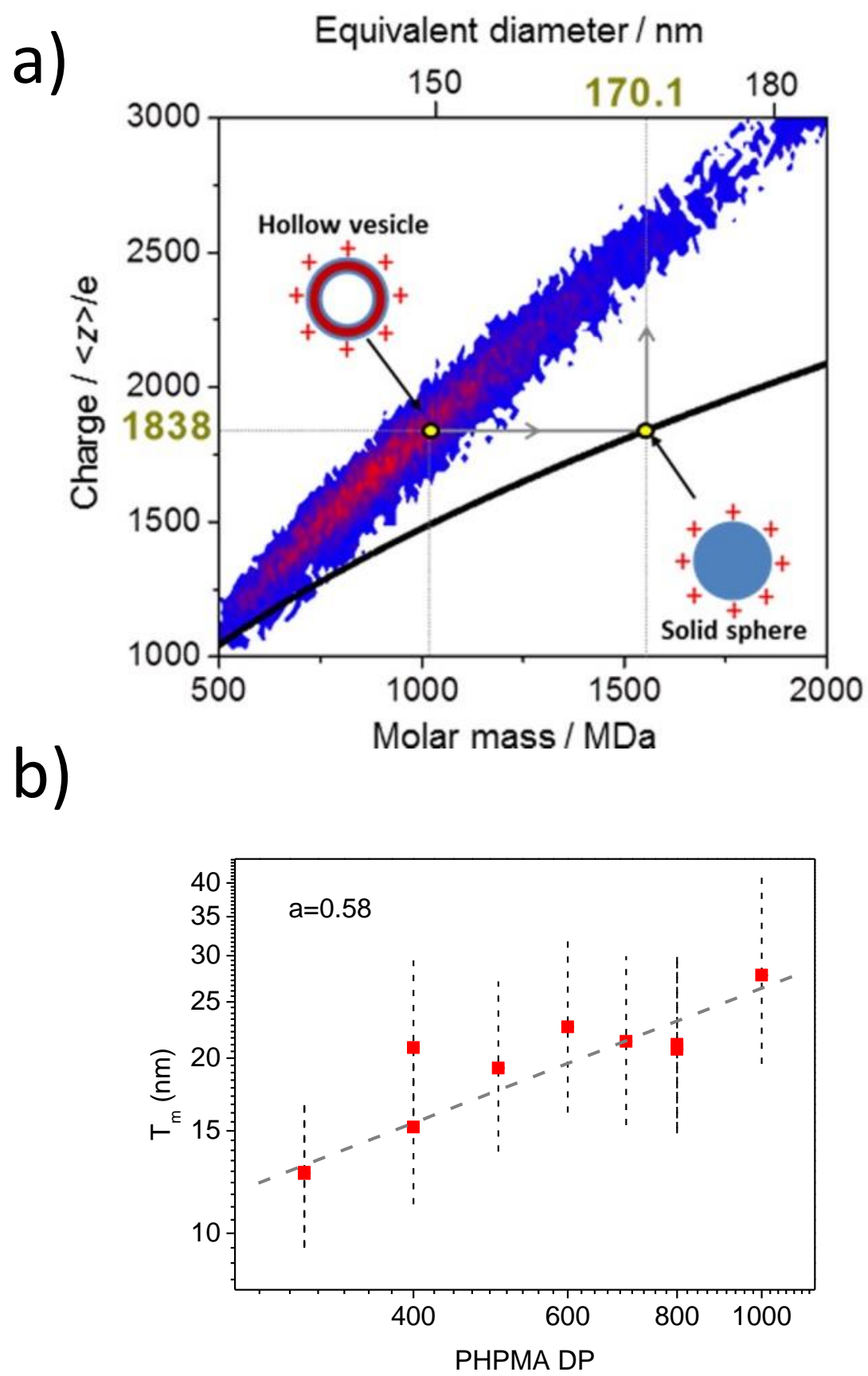

Figure $3:$ a) 3D mass-charge image of ionised polymer vesicles obtained via CDMS together with the predicted Rayleigh's limiting charge at $60 \%$ as a function of the molar mass. b) Evolution of membrane thickness (T) with PHPMA DP for a series of block-copolymer vesicles as extracted by CDMS. The bars indicate the thickness assuming charging of vesicles from $50 \%$ to $70 \%$ of the Rayleigh's limiting charge of charged water droplet of the same dimensions. (adapted from ref. 54). 


\section{Multidimensional CDMS : Couplings with separation and dissociation techniques}

While the above examples have demonstrated the interest of CDMS as an efficient MS-based tool for the characterization of large polymers, two areas are still not correctly addressed by this technique for polymer analysis: (i) information on the chemical composition (and end-group termination) of polymers of ultra-high molar mass and (ii) characterization of complex polymer samples.

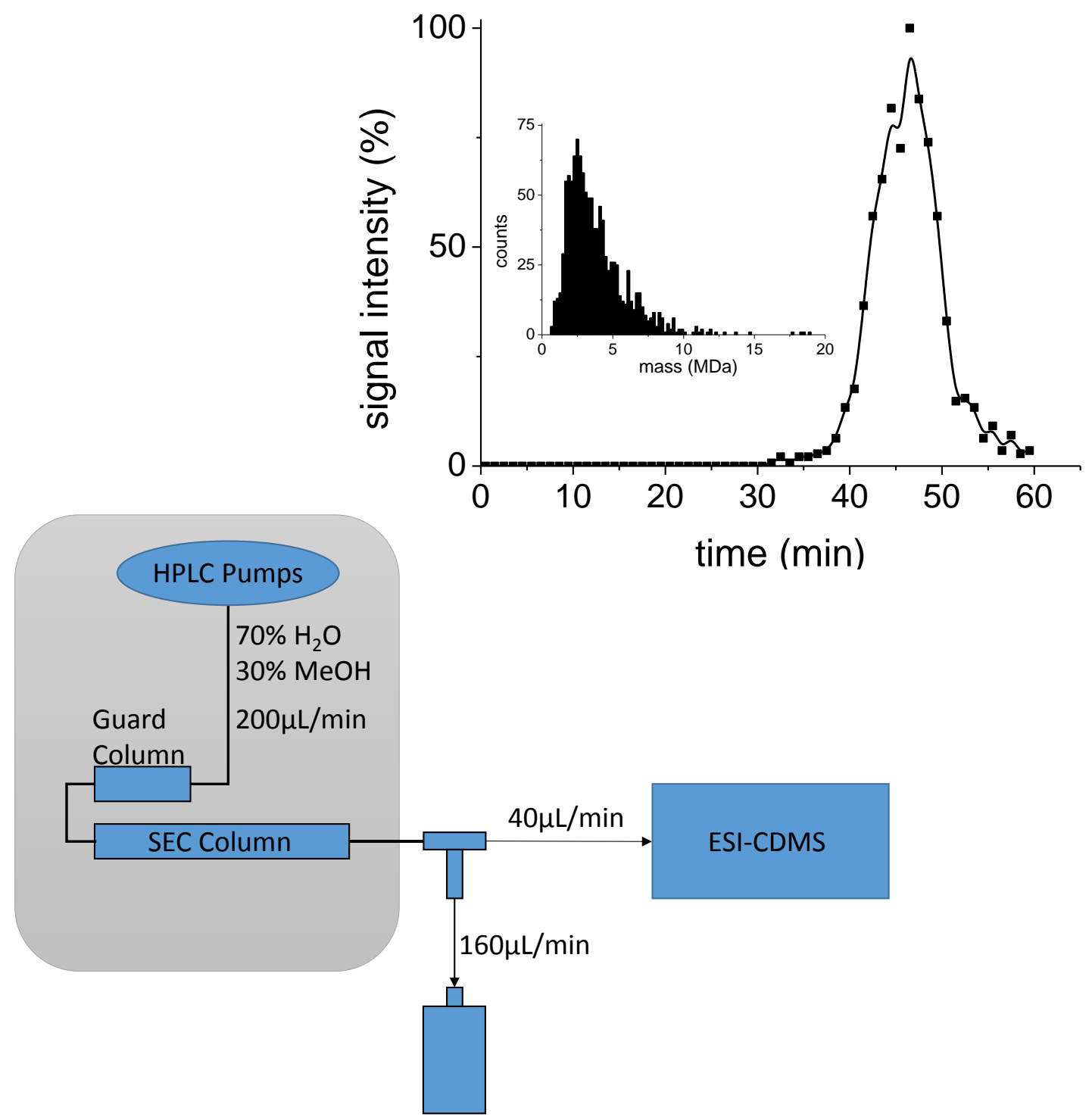

Figure 4 : Experimental setup for the online SEC-ESI-CDMS coupling. SEC-ESI-CDMS (black squares, fitted with a regular line to guide the eyes) profiles of PAMPS (2.0 mg mL-1). Inset: Histogram mass spectrum of the integrated SEC-ESI-CDMS peak. (adapted from ref. 41).

Clearly, the 2D mass-charge map (obtained by single pass-CDMS) can help in getting insight into the composition of heterogeneous and complex samples, as it was demonstrated for complex amyloid 
fibril samples. ${ }^{[59]}$ However, interfacing CDMS with a separation method would help to better discriminate complex polymer samples. Size-exclusion chromatography (SEC) separates a polymer sample in solution by the size of the polymer chains. ${ }^{[83]}$ At a given elution time, a fraction of the total polymer molecular weight distribution is contained in the solvent eluting from the packed column.

Coupling size-exclusion chromatography (SEC) with mass spectrometry (MS) benefits from a mutual interest. In one hand, SEC would help to better discriminate complex polymer samples for MS analysis and in other hand, MS analysis will generate a SEC calibration curve based on the analyte itself, which is more reliable than calibration based on non-related standards and faster than the use of the multiple detection mode. Since $>1000$ ions per second can be analyzed with single-pass CDMS, this fast MS technique can efficiently sample SEC chromatograms which take several tens of minutes (see Fig. 4). We used columns specifically conceived to allow mass analysis of synthetic polymers of over $15 \mathrm{MDa}$, and the performance of the SEC-single pass CDMS coupling was evaluated for polyacrylamide (PAM, 5-6 MDa) and a poly(2-acrylamido-2-methyl-1-propanesulfonic acid) (PAMPS, $2 \mathrm{MDa}$ ) polymer samples. ${ }^{[41]} \mathrm{A}$ retention time of $\sim 45 \mathrm{~min}$ and a peak width of about 6 min were measured in the SEC/CDMS chromatogram obtained for PAMPS (see Fig. 4). SEC/ESI-CDMS data display molecular weight distributions and mass values consistent with data provided by the sample supplier. This coupling thus afforded an attractive solution for SEC calibration without the use of external standards.

Single pass CDMS presents a poor mass resolution and cannot discriminate individual mass from the macromolecule in the distribution, each separated by monomer units. Thus no structural information can be drawn from the mass distribution obtained by single pass CDMS analysis. Fortunately, tandem mass spectrometry (MS/MS) is able to provide structural information. Usually, an excess of internal energy is deposited to the parent molecular ions resulting in its fragmentation. In our group, we upgraded our charge detection device in order to trap single ions thanks to electrostatic mirrors at each side of the detection tube ("Benner" trap). ${ }^{[45-47,49,52,55]}$ In this configuration, a single macroion selected in mass and charge can be trapped in this "Benner" trap during several tens of milliseconds, which corresponds to several hundreds of oscillations. The first benefit is that we can re-measure charge and time-of-flight as many times as the ion oscillates in the trap improving the $z$ and $\mathrm{m} / \mathrm{z}$ precision of CD-MS measurements by a factor that can reach 25. ${ }^{[45]}$ During their storage time, single ions can be irradiated by the $\mathrm{CO}_{2}$ laser. The $\mathrm{CO}_{2}$ laser provides low-energy $0.1 \mathrm{eV}$ infra-red photons. ${ }^{[42]}$ Macroions can be efficiently heated and thus fragmented by multiple absorption of IR photons (infrared multi-photon dissociation (IRMPD) experiments). Trajectory simulations employing SIMION showed that fragment ions can be still trapped when they are generated in the field-free 
region (they will have the same velocity as the parent ion). ${ }^{[4]}$ Thus, in this particular case, the "Benner trap" behaves like an MS/MS instrument, where the $m / z$ of both parent and fragments can be extracted when single ions fragments in two parts (asymmetric fission). The charge and time-offlight of parent and fragment ions can be detected separately. Only the largest fragmentation products generated from IR multiphoton absorption of megadalton polymers can measured and we showed for PAMPS polymers of 2 MDa average molecular mass that such fragments have higher $\mathrm{m} / \mathrm{z}$ ratios than the $\mathrm{m} / \mathrm{z}$ of their precursor ions. In other words, polymer ions lose more charge than mass when fragmenting. On average, the largest fragmentation ions hold $\sim 75 \%$ of the total parent charge. The results are similar for both cations and anions. ${ }^{[47]}$

\section{Conclusion and Outlooks}

The ability to generate macromolecular ions in the gas phase from a polymer sample and acquire high-resolution mass spectra, has really push the envelope of mass spectrometry towards the determination of information about the compositional and molecular weight distributions of polymers in the kilodalton range. For heavier polymer ions (e.g. in the mega- to giga-dalton range), the difficulties that exist in their analysis are largely due to the broad and complex distribution of species with different molecular masses.

Charge detection mass spectrometry, and in particular its single-pass mode, in spite of a moderate mass resolution, appears to be a rapid and efficient MS-based technique for the weighing of ultrahigh molar mass and polymeric nanomaterials. Direct mass measurements on thousands of single ions allows for a precise determination of dispersity. Also, in addition to mass measurements, charge measurements allows for complementary information. In particular, due to its sensitivity to the ionizable groups at the surface of macromolecular ions, the total charge is an indirect probe of morphology of synthetic polymers of ultra-high molecular weight and polymeric nanomaterials. By interfacing single-pass CDMS with a chromatography technique (SEC), we demonstrated that hyphenated separation approaches can lead to efficient reduction of complexity for polymer characterization. Other separation couplings with CDMS, such as field-flow fractionation ${ }^{[84]}$ based techniques might be possible. This multidimensional mass spectrometry can be also developed after ionization, in particular using ion-mobility mass spectrometry. Recently, Williams and coworkers have shown that not only mass and charge but also cross sectional information can be obtained by CDMS, which can be used to directly explore structures of heavy molecules. ${ }^{\left[{ }^{[5-87]}\right.}$ Here, electrostatic mirrors at each side of the detection tube of CDMS have been implemented and trapped ions collide with 
background gas, which leads to frequency shifts (see Fig. 5). From the amount and the intervals of the frequency, the collision cross section can be evaluated. The simultaneous measurements of mass and collisional cross-section of single ions with charge detection mass spectrometry might be a more direct probe of morphology of synthetic polymers of ultra-high molecular weight and polymeric nanomaterials (than charge measurements).

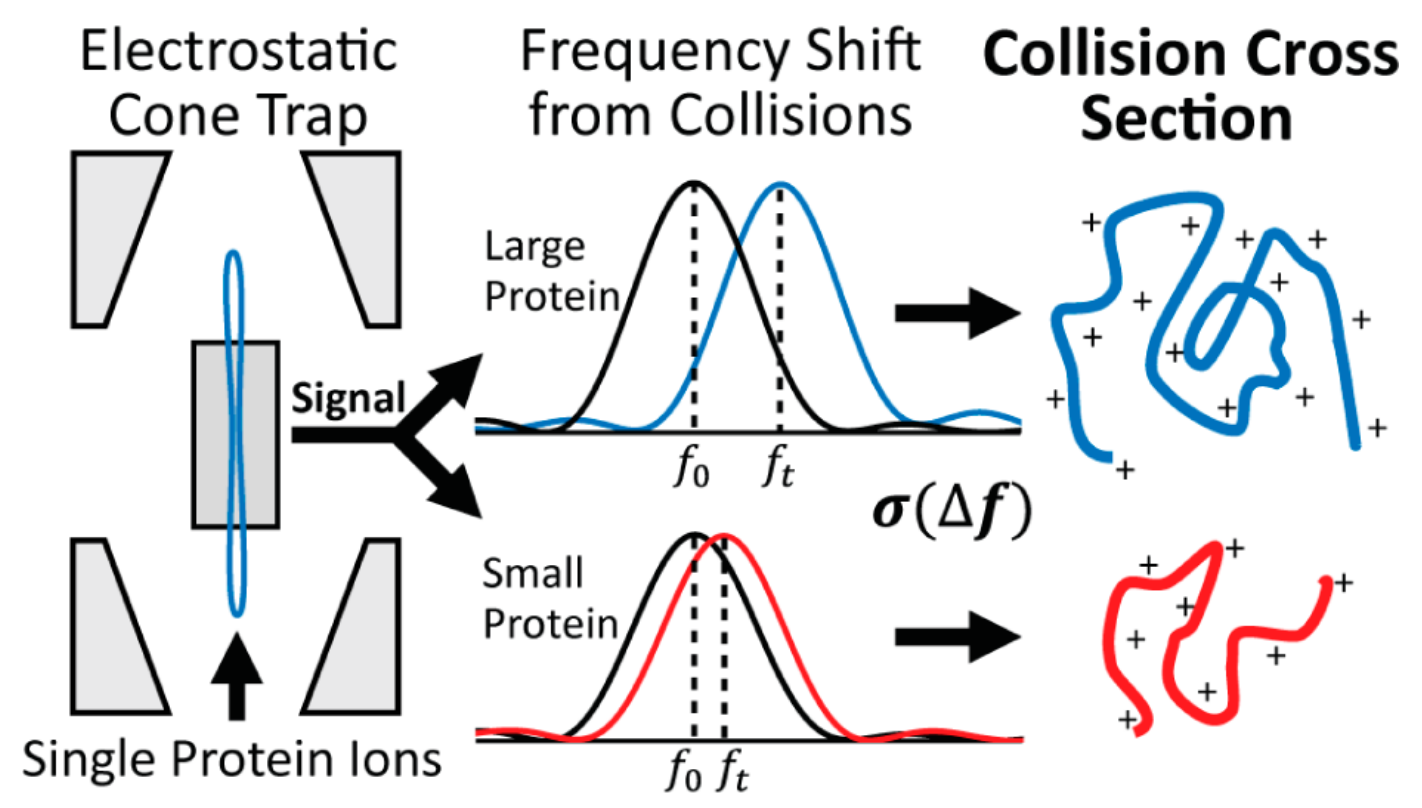

Figure 5 : Principles of simultaneous measurements of mass and collisional cross-section of single ions with charge detection mass spectrometry. (adapted from ref. 86).

Also, tandem mass spectrometry (MS/MS) is able to provide structural information. As a proof of concept, we demonstrated that single trapped ions can be irradiated by the $\mathrm{CO}_{2}$ laser leading to photofragmentation patterns. Unfortunately, the "Benner trap" is more a storage device than really a MS/MS instrument, and only limited information on fragments can be obtained. Clearly, more sophisticated MS/MS coupling should be developed for providing structural information on synthetic polymers of ultra-high molecular weight and polymeric nanomaterials. For example, hybrid tandem mass spectrometer can be obtained by combining a linear quadrupole ion trap (QLIT) with a linear electrostatic ion trap (electrostatic mirrors at each side of a detection tube), as demonstrated by McLuckey and coworkers. ${ }^{[88]}$ In this coupling, the QLIT was used both as an accumulation device for the pulsed injection of ions into the ion trap and as a collision cell for ions released from the trap and back into the QLIT. One can imagine that the QLIT can also be used as a MS device to probe the nature of low fragment ions coming from the photofragmentation of irradiated precursor ions stored in the ion trap. Other MS/MS couplings with the ion trap, such as time-of-flight MS might be possible. 
Concerning polymeric nanomaterials, the CDMS device developed in Lyon represents a new analytical methodology for the mass characterization of nano-objects, which is part of the crucial need to develop new tools for nanometrology. The charge detection mass spectrometry could constitute a technological breakthrough vis-à-vis the usual techniques of size characterization such as electron microscopy and the scattering of light, among others. In parallel, other technologies ${ }^{[75,89-94]}$ have recently been proposed as mass spectrometry based tools for nanometrology. For example, nanomechanical resonators with the size of several hundreds of $\mathrm{nm}$ detect and measure the mass of nanoparticles. ${ }^{[95]}$ Recently, Masselon, Hentz, et al. combined nano-electrospray ionization with aerodynamic lens to ionize and efficiently focus a particle beam which hits a detector composes by an array of 20 nanomechanical resonators etched into a silicon chip. ${ }^{[96,97]}$

\section{Acknowledgements}

The French National Research Agency (ANR) is acknowledged for financial support of this work (ANR08-BLAN-0110-01 and ANR-11-PDOC-032-01). I would like to thank Xavier Dagany, Christian Clavier, Michel Kerleroux, Marc Barbaire, Jacques Maurelli for their invaluable technical assistance together with Philippe Dugourd, Franck Bertorelle, Cong-Yu Bao, Marion Santacreu, Nesrine Ouadah, Thomas Hamada, Pierre Paletto, Arthur Viodé, Caroline Bourgeois, Mohammad A. Halim, Hussein Fakhouri for their contribution. Tristan Doussineau was a post-doctorate researcher in my group for five years, built the CDMS instrument and its coupling with laser induced fragmentation. Finally, I would like to warmly thank Laurence Charles for her constant support, encouragement and fruitful discussions and valuable feedbacks.

\section{References}

[1] S. Podzimek, in Encyclopedia of Analytical Science (Third Edition) (Eds.: P. Worsfold, C. Poole, A. Townshend, M. Miró), Academic Press, Oxford, 2019, pp. 360.

[2] L. Bokobza. Spectroscopic Techniques for the Characterization of Polymer Nanocomposites: A Review. Polymers 2018, 10, 7.

[3] S. A. Umoren, M. M. Solomon, in Polymer science: research advances, practical applications and educational aspects (Ed.: A. S. A. Méndez-Vilas), Formatex Reserach Center, 2016.

[4] R. P. L. G.Montaudo, Mass Spectrometry of Polymers, CRC Press, Boca Raton, 2002.

[5] J. Fenn, M. Mann, C. Meng, S. Wong, C. Whitehouse. Electrospray ionization for mass spectrometry of large biomolecules. Science 1989, 246, 64.

[6] M. Karas, F. Hillenkamp. Laser desorption ionization of proteins with molecular masses exceeding 10,000 daltons. Analytical Chemistry 1988, 60, 2299.

[7] K. Tanaka, H. Waki, Y. Ido, S. Akita, Y. Yoshida, T. Yoshida, T. Matsuo. Protein and polymer analyses up to $\mathrm{m} / \mathrm{z} 100000$ by laser ionization time-of-flight mass spectrometry. Rapid Communications in Mass Spectrometry 1988, 2, 151. 
[8] S. D. Hanton. Mass Spectrometry of Polymers and Polymer Surfaces. Chemical Reviews 2001, $101,527$.

[9] T. Gruendling, S. Weidner, J. Falkenhagen, C. Barner-Kowollik. Mass spectrometry in polymer chemistry: a state-of-the-art up-date. Polymer Chemistry 2010, 1, 599.

[10] C. Wesdemiotis. Multidimensional Mass Spectrometry of Synthetic Polymers and Advanced Materials. Angewandte Chemie International Edition 2017, 56, 1452.

[11] L. Charles. MALDI of synthetic polymers with labile end-groups. Mass Spectrometry Reviews 2014, 33, 523.

[12] C. A. Jackson, W. J. Simonsick. Application of mass spectrometry to the characterization of polymers. Current Opinion in Solid State and Materials Science 1997, 2, 661.

[13] N. Aminlashgari, M. Hakkarainen. Emerging mass spectrometric tools for analysis of polymers and polymer additives. Adv. Polym. Sci. 2012, 248, 1.

[14] S. M. Weidner, S. Trimpin. Mass Spectrometry of Synthetic Polymers. Analytical Chemistry 2010, 82, 4811.

[15] P. B. O'Connor, F. W. McLafferty. Oligomer Characterization of 4-23 kDa Polymers by Electrospray Fourier Transform Mass Spectrometry. Journal of the American Chemical Society 1995, 117, 12826.

[16] A. A. Aksenov, M. E. Bier. The analysis of polystyrene and polystyrene aggregates into the mega dalton mass range by cryodetection MALDI TOF MS. J Am Soc Mass Spectrom 2008, 19, 219.

[17] R. Mueller, G. Allmaier. Molecular weight determination of ultra-high mass compounds on a standard matrix-assisted laser desorption/ionization time-of-flight mass spectrometer: PAMAM dendrimer generation 10 and immunoglobulin M. Rapid Commun. Mass Spectrom. 2006, 20, 3803.

[18] H. J. Raeder, T.-T.-T. Nguyen, K. Muellen. MALDI-TOF Mass Spectrometry of Polyphenylene Dendrimers up to the Megadalton Range. Elucidating Structural Integrity of Macromolecules at Unrivaled High Molecular Weights. Macromolecules (Washington, DC, U. S.) 2014, 47, 1240.

[19] S. J. Gabriel, R. F. Steinhoff, M. Pabst, C. Schwarzinger, R. Zenobi, U. Panne, S. M. Weidner. Improved analysis of ultra-high molecular mass polystyrenes in matrix-assisted laser desorption/ionization time-of-flight mass spectrometry using DCTB matrix and caesium salts. Rapid Communications in Mass Spectrometry 2015, 29, 1039.

[20] D. C. Schriemer, L. Li. Detection of High Molecular Weight Narrow Polydisperse Polymers up to 1.5 Million Daltons by MALDI Mass Spectrometry. Analytical Chemistry 1996, 68, 2721.

[21] H. J. Räder, T.-T.-T. Nguyen, K. Müllen. MALDI-TOF Mass Spectrometry of Polyphenylene Dendrimers up to the Megadalton Range. Elucidating Structural Integrity of Macromolecules at Unrivaled High Molecular Weights. Macromolecules 2014, 47, 1240.

[22] S. D. Fuerstenau, W. H. Benner. Molecular weight determination of megadalton DNA electrospray ions using charge detection time-of-flight mass spectrometry. Rapid Commun. Mass Spectrom 1995, 9, 1528.

[23] H. Shelton, C. D. H. Jr., R. F. Wuerker. Electrostatic Acceleration of Microparticles to Hypervelocities. Journal of Applied Physics 1960, 31, 1243.

[24] D. Z. Keifer, M. F. Jarrold. Single-molecule mass spectrometry. Mass Spectrom. Rev. 2016, n/a.

[25] D. Z. Keifer, E. E. Pierson, M. F. Jarrold. Charge detection mass spectrometry: weighing heavier things. Analyst 2017, 142, 1654.

[26] H. Fakhoury, M. Perić, F. Bertorelle, P. Dugourd, x. dagany, I. Russier-Antoine, P.-F. Brevet, V. Bonacic-Koutecky, R. Antoine. Sub-100-nanometer Silver Doped Gold-Cysteine Supramolecular Assemblies with Enhanced Nonlinear Optical Properties. Physical Chemistry Chemical Physics 2019. 
[27] C. A. Lutomski, S. M. Gordon, A. T. Remaley, M. F. Jarrold. Resolution of Lipoprotein Subclasses by Charge Detection Mass Spectrometry. Analytical Chemistry 2018, 90, 6353.

[28] C. A. Dunbar, H. M. Callaway, C. R. Parrish, M. F. Jarrold. Probing Antibody Binding to Canine Parvovirus with Charge Detection Mass Spectrometry. Journal of the American Chemical Society 2018, 140, 15701.

[29] D. Z. Keifer, T. Motwani, C. M. Teschke, M. F. Jarrold. Measurement of the accurate mass of a 50 MDa infectious virus. Rapid Communications in Mass Spectrometry 2016, 30, 1957.

[30] D. Z. Keifer, E. E. Pierson, J. A. Hogan, G. J. Bedwell, P. E. Prevelige, M. F. Jarrold. Charge detection mass spectrometry of bacteriophage P22 procapsid distributions above $20 \mathrm{MDa}$. Rapid Communications in Mass Spectrometry 2014, 28, 483.

[31] A. A. Kukreja, J. C. Y. Wang, E. Pierson, D. Z. Keifer, L. Selzer, Z. Tan, B. Dragnea, M. F. Jarrold, A. Zlotnick. Structurally Similar Woodchuck and Human Hepadnavirus Core Proteins Have Distinctly Different Temperature Dependences of Assembly. Journal of Virology 2014, 88, 14105.

[32] L. S. Lee, N. Brunk, D. G. Haywood, D. Keifer, E. Pierson, P. Kondylis, J. C. Y. Wang, S. C. Jacobson, M. F. Jarrold, A. Zlotnick. A molecular breadboard: Removal and replacement of subunits in a hepatitis B virus capsid. Protein Science 2017, 26, 2170.

[33] C. A. Lutomski, N. A. Lyktey, E. E. Pierson, Z. C. Zhao, A. Zlotnick, M. F. Jarrold. Multiple Pathways in Capsid Assembly. Journal of the American Chemical Society 2018, 140, 5784.

[34] C. A. Lutomski, N. A. Lyktey, Z. C. Zhao, E. E. Pierson, A. Zlotnick, M. F. Jarrold. Hepatitis B Virus Capsid Completion Occurs through Error Correction. Journal of the American Chemical Society 2017, 139, 16932.

[35] E. E. Pierson, D. Z. Keifer, L. Selzer, L. S. Lee, N. C. Contino, J. C. Y. Wang, A. Zlotnick, M. F. Jarrold. Detection of Late Intermediates in Virus Capsid Assembly by Charge Detection Mass Spectrometry. Journal of the American Chemical Society 2014, 136, 3536.

[36] L. Delalande, I. B. Tsvetkova, C. Zeng, K. Bond, M. F. Jarrold, B. Dragnea. Catching a virus in a molecular net. Nanoscale 2016, 8, 16221.

[37] S. D. Fuerstenau, W. H. Benner, J. J. Thomas, C. Brugidou, B. Bothner, G. Siuzdak. Mass Spectrometry of an Intact Virus. Angewandte Chemie International Edition 2001, 40, 541.

[38] D. Z. Keifer, A. W. Alexander, M. F. Jarrold. Spontaneous Mass and Charge Losses from Single Multi-Megadalton lons Studied by Charge Detection Mass Spectrometry. Journal of the American Society for Mass Spectrometry 2017, 28, 498.

[39] E. E. Pierson, D. Z. Keifer, A. Asokan, M. F. Jarrold. Resolving Adeno-Associated Viral Particle Diversity With Charge Detection Mass Spectrometry. Analytical Chemistry 2016, 88, 6718.

[40] E. E. Pierson, D. Z. Keifer, A. A. Kukreja, J. C. Y. Wang, A. Zlotnick, M. F. Jarrold. Charge Detection Mass Spectrometry Identifies Preferred Non-Icosahedral Polymorphs in the SelfAssembly of Woodchuck Hepatitis Virus Capsids. Journal of Molecular Biology 2016, 428, 292.

[41] A. Viode, X. Dagany, M. Kerleroux, P. Dugourd, T. Doussineau, L. Charles, R. Antoine. Coupling of size-exclusion chromatography with electrospray ionization charge-detection mass spectrometry for the characterization of synthetic polymers of ultra-high molar mass. Rapid Communications in Mass Spectrometry 2016, 30, 132.

[42] T. Doussineau, C. Y. Bao, C. Clavier, X. Dagany, M. Kerleroux, R. Antoine, P. Dugourd. Infrared multiphoton dissociation tandem charge detection-mass spectrometry of single megadalton electrosprayed ions. Review of Scientific Instruments 2011, 82.

[43] T. Doussineau, R. Antoine, M. Santacreu, P. Dugourd. Pushing the Limit of Infrared Multiphoton Dissociation to Megadalton-Size DNA lons. Journal of Physical Chemistry Letters 2012, 3, 2141.

[44] R. Antoine, T. Doussineau, P. Dugourd, F. Calvo. Multiphoton dissociation of macromolecular ions at the single-molecule level. Physical Review A 2013, 87. 
[45] T. Doussineau, P. Paletto, P. Dugourd, R. Antoine. Multiphoton Dissociation of Electrosprayed MegaDalton-Sized DNA lons in a Charge-Detection Mass Spectrometer. Journal of the American Society for Mass Spectrometry 2015, 26, 7.

[46] M. A. Halim, F. Bertorelle, T. Doussineau, R. Antoine. Direct determination of molecular weight distribution of calf-thymus DNAs and study of their fragmentation under ultrasonic and low-energy infrared irradiations. A charge detection mass spectrometry investigation. Rapid Communications in Mass Spectrometry 2019, 0 .

[47] M. A. Halim, C. Clavier, X. Dagany, M. Kerleroux, P. Dugourd, R. C. Dunbar, R. Antoine. Infrared laser dissociation of single megadalton polymer ions in a gated electrostatic ion trap: the added value of statistical analysis of individual events. Physical Chemistry Chemical Physics 2018, 20, 11959.

[48] T. Doussineau, M. Kerleroux, X. Dagany, C. Clavier, M. Barbaire, J. Maurelli, R. Antoine, P. Dugourd. Charging megadalton poly(ethylene oxide)s by electrospray ionization. A charge detection mass spectrometry study. Rapid Commun. Mass Spectrom. 2011, 25, 617.

[49] T. Doussineau, C. Y. Bao, R. Antoine, P. Dugourd, W. Zhang, F. D'Agosto, B. Charleux. Direct Molar Mass Determination of Self-Assembled Amphiphilic Block Copolymer Nanoobjects Using Electrospray-Charge Detection Mass Spectrometry. ACS Macro Lett. 2012, 1, 414.

[50] T. Doussineau, M. Santacreu, R. Antoine, P. Dugourd, W. J. Zhang, I. Chaduc, M. Lansalot, F. D'Agosto, B. Charleux. The Charging of Micellar Nanoparticles in Electrospray lonization. Chemphyschem 2013, 14, 603.

[51] N. Ouadah, T. Doussineau, T. Hamada, P. Dugourd, C. Bordes, R. Antoine. Correlation between the Charge of Polymer Particles in Solution and in the Gas Phase Investigated by Zeta-Potential Measurements and Electrospray lonization Mass Spectrometry. Langmuir 2013, 29, 14074.

[52] I. Chaduc, J. Parvole, T. Doussineau, R. Antoine, A. Desert, P. Y. Dugas, S. Ravaine, E. Duguet, E. Bourgeat-Lami, M. Lansalot. Towards a one-step method for preparing silica/polymer heterodimers and dimpled polymer particles. Polymer 2015, 70, 118.

[53] T. Doussineau, A. Desert, O. Lambert, J. C. Taveau, M. Lansalot, P. Dugourd, E. BourgeatLami, S. Ravaine, E. Duguet, R. Antoine. Charge Detection Mass Spectrometry for the Characterization of Mass and Surface Area of Composite Nanoparticles. Journal of Physical Chemistry C 2015, 119, 10844.

[54] N. J. Warren, O. O. Mykhaylyk, A. J. Ryan, M. Williams, T. Doussineau, P. Dugourd, R. Antoine, G. Portale, S. P. Armes. Testing the Vesicular Morphology to Destruction: Birth and Death of Diblock Copolymer Vesicles Prepared via Polymerization-Induced Self-Assembly. Journal of the American Chemical Society 2015, 137, 1929.

[55] A. Faucon, H. Benhelli-Mokrani, F. Fleury, L. Dubreil, P. Hulin, S. Nedellec, T. Doussineau, R. Antoine, T. Orlando, A. Lascialfari, J. Fresnais, L. Lartigue, E. Ishow. Tuning the architectural integrity of high-performance magneto-fluorescent core-shell nanoassemblies in cancer cells. Journal of Colloid and Interface Science 2016, 479, 139.

[56] M. Loumaigne, C. Midelet, T. Doussineau, P. Dugourd, R. Antoine, M. Stamboul, A. Debarre, M. H. V. Werts. Optical extinction and scattering cross sections of plasmonic nanoparticle dimers in aqueous suspension. Nanoscale 2016, 8, 6555.

[57] T. Doussineau, C. Mathevon, L. Altamura, C. Vendrely, P. Dugourd, V. Forge, R. Antoine. Mass Determination of Entire Amyloid Fibrils by Using Mass Spectrometry. Angewandte ChemieInternational Edition 2016, 55, 2340.

[58] R. Bascetin, K. Admane, R. Agniel, T. Boudou, T. Doussineau, R. Antoine, O. Gallet, J. LeroyDudal, C. Vendrely. Amyloid-like aggregates formation by blood plasma fibronectin. International Journal of Biological Macromolecules 2017, 97, 733.

[59] J. Pansieri, M. A. Halim, C. Vendrely, M. Dumoulin, F. Legrand, M. M. Sallanon, S. Chierici, S. Denti, X. Dagany, P. Dugourd, C. Marquette, R. Antoine, V. Forge. Mass and charge 
distributions of amyloid fibers involved in neurodegenerative diseases: mapping

heterogeneity and polymorphism. Chemical Science 2018, 9, 2791.

[60] J. B. Fenn, M. Mann, C. K. Meng, S. F. Wong, C. M. Whitehouse. Electrospray ionizationprinciples and practice. Mass Spectrometry Reviews 1990, 9, 37.

[61] J. T. Maze, T. C. Jones, M. F. Jarrold. Negative droplets from positive electrospray. Journal of Physical Chemistry A 2006, 110, 12607.

[62] L. W. Zilch, J. T. Maze, J. W. Smith, G. E. Ewing, M. F. Jarrold. Charge Separation in the Aerodynamic Breakup of Micrometer-Sized Water Droplets. Journal of Physical Chemistry A 2008, 112, 13352.

[63] L. W. Zilch, J. T. Maze, J. W. Smith, M. F. Jarrold. Freezing, fragmentation, and charge separation in sonic sprayed water droplets. International Journal of Mass Spectrometry 2009, 283, 191.

[64] Q. Duez, H. Metwally, L. Konermann. Electrospray Ionization of Polypropylene Glycol: Rayleigh-Charged Droplets, Competing Pathways, and Charge State-Dependent Conformations. Anal. Chem. 2018, 90, 9912.

[65] D. Gerlich, Inhomogeneous RF Fields: A Versatile Tool for the Study of Processes with Slow Ions. in Advances in Chemical Physics (eds. C. Ng, M. Baer, I. Prigogine and S. A. Rice), 2007.

[66] R. R. Julian, S. R. Mabbett, M. F. Jarrold. Ion funnels for the masses: Experiments and simulations with a simplified ion funnel. Journal of the American Society for Mass Spectrometry 2005, 16, 1708.

[67] B. E. Draper, S. N. Anthony, M. F. Jarrold. The FUNPET-a New Hybrid Ion Funnel-lon Carpet Atmospheric Pressure Interface for the Simultaneous Transmission of a Broad Mass Range. Journal of The American Society for Mass Spectrometry 2018, 29, 2160.

[68] B. D. Adamson, M. E. C. Miller, R. E. Continetti. The aerosol impact spectrometer: a versatile platform for studying the velocity dependence of nanoparticle-surface impact phenomena. EPJ Techniques and Instrumentation 2017, 4, 2.

[69] J. E. Bruce, X. Cheng, R. Bakhtiar, Q. Wu, S. A. Hofstadler, G. A. Anderson, R. D. Smith. Trapping, Detection, and Mass Measurement of Individual Ions in a Fourier-Transform IonCyclotron Resonance Mass-Spectrometer. Journal of the American Chemical Society 1994, 116, 7839.

[70] C. Muddiman David, D. Smith Richard, in Reviews in Analytical Chemistry, Vol. 17, 1998, p. 1.

[71] R. D. Smith, X. Cheng, J. E. Bruce, S. A. Hofstadler, G. A. Anderson. Trapping, Detection and Reaction of Very Large Single Molecular-lons by Mass-Spectrometry. Nature 1994, 369, 137.

[72] R. J. Rose, E. Damoc, E. Denisov, A. Makarov, A. J. R. Heck. High-sensitivity Orbitrap mass analysis of intact macromolecular assemblies. Nature Methods 2012, 9, 1084.

[73] D. J. Griffiths, Introduction to Electrodynamics,3rd Edition, Prentice Hall, 2007.

[74] D. Fantini, M. Zanetti, L. Costa. Polystyrene Microspheres and Nanospheres Produced by Electrospray. Macromolecular Rapid Communications 2006, 27, 2038.

[75] W.-P. Peng, S.-W. Chou, A. A. Patil. Measuring masses of large biomolecules and bioparticles using mass spectrometric techniques. Analyst 2014, 139, 3507.

[76] W. H. Benner. A gated electrostatic ion trap to repetitiously measure the charge and $\mathrm{m} / \mathrm{z}$ of large electrospray ions. Anal. Chem. 1997, 69, 4162.

[77] A. G. Elliott, S. I. Merenbloom, S. Chakrabarty, E. R. Williams. Single Particle Analyzer of Mass: A Charge Detection Mass Spectrometer with a Multi-Detector Electrostatic lon Trap. Int. J. Mass Spectrom. 2017, 414, 45.

[78] J. Fernandez de la Mora. Electrospray ionization of large multiply charged species proceeds via Dole's charged residue mechanism. Analytica Chimica Acta 2000, 406, 93.

[79] S. D. Fuerstenau, W. H. Benner. Molecular weight determination of megadalton DNA electrospray ions using charge detection time-of-flight mass spectrometry. Rapid Communications in Mass Spectrometry 1995, 9, 1528. 
[80] J. C. Schultz, C. A. Hack, W. H. Benner. Mass determination of megadalton-DNA electrospray ions using charge detection mass spectrometry. Journal of the American Society for Mass Spectrometry 1998, 9, 305.

[81] J. C. Schultz, C. A. Hack, W. H. Benner. Polymerase chain reaction products analyzed by charge detection mass spectrometry. Rapid Communications in Mass Spectrometry 1999, 13, 15.

[82] D. Nichetti, I. Manas-Zloczower. Viscosity model for polydisperse polymer melts. Journal of Rheology 1998, 42, 951.

[83] T. Chang, in Liquid Chromatography / FTIR Microspectroscopy / MicrowaveAssisted Synthesis, Springer Berlin Heidelberg, Berlin, Heidelberg, 2003, pp. 1.

[84] M. I. Malik, H. Pasch. Field-flow fractionation: New and exciting perspectives in polymer analysis. Progress in Polymer Science 2016, 63, 42.

[85] A. G. Elliott, C. C. Harper, H.-W. Lin, A. C. Susa, Z. Xia, E. R. Williams. Simultaneous Measurements of Mass and Collisional Cross-Section of Single lons with Charge Detection Mass Spectrometry. Anal. Chem. (Washington, DC, U. S.) 2017, 89, 7701.

[86] A. G. Elliott, C. C. Harper, H.-W. Lin, E. R. Williams. Mass, mobility and MSn measurements of single ions using charge detection mass spectrometry. Analyst 2017, 142, 2760.

[87] C. C. Harper, A. G. Elliott, H.-W. Lin, E. R. Williams. Determining Energies and Cross Sections of Individual lons Using Higher-Order Harmonics in Fourier Transform Charge Detection Mass Spectrometry (FT-CDMS). Journal of The American Society for Mass Spectrometry 2018, 29, 1861.

[88] R. T. Hilger, R. E. Santini, S. A. McLuckey. Nondestructive Tandem Mass Spectrometry Using a Linear Quadrupole Ion Trap Coupled to a Linear Electrostatic Ion Trap. Analytical Chemistry 2013, 85, 5226.

[89] Y. Cai, W. P. Peng, H. C. Chang. Ion Trap Mass Spectrometry of Fluorescently Labeled Nanoparticles. Anal. Chem. 2003, 75, 1805.

[90] Y. Cai, W. P. Peng, S. J. Kuo, S. Sabu, C. C. Han, H. C. Chang. Optical Detection and ChargeState Analysis of MALDI-Generated Particles with Molecular Masses Larger Than 5 MDa. Anal. Chem. 2002, 74, 4434.

[91] W. P. Peng, Y. Cai, Y. T. Lee, H. C. Chang. Laser-induced fluorescence/ion trap as a detector for mass spectrometric analysis of nanoparticles. Int. J. Mass Spectrom. 2003, $229,67$.

[92] W.-P. Peng, Y. Cai, H.-C. Chang. Optical detection methods for mass spectrometry of macroions. Mass Spectrom. Rev. 2004, 23, 443.

[93] W.-P. Peng, Y.-C. Yang, C.-W. Lin, H.-C. Chang. Molar Mass and Molar Mass Distribution of Polystyrene Particle Size Standards. Anal. Chem. 2005, 77, 7084.

[94] Z. Zhu, C. Xiong, G. Xu, H. Liu, X. Zhou, R. Chen, W.-P. Peng, Z. Nie. Characterization of bioparticles using a miniature cylindrical ion trap mass spectrometer operated at rough vacuum. Analyst (Cambridge, U. K.) 2011, 136, 1305.

[95] A. K. Naik, M. S. Hanay, W. K. Hiebert, X. L. Feng, M. L. Roukes. Towards single-molecule nanomechanical mass spectrometry. Nat Nano 2009, 4, 445.

[96] S. Dominguez-Medina, S. Fostner, M. Defoort, M. Sansa, A.-K. Stark, M. A. Halim, E. Vernhes, M. Gely, G. Jourdan, T. Alava, P. Boulanger, C. Masselon, S. Hentz. Neutral mass spectrometry of virus capsids above 100 megadaltons with nanomechanical resonators. Science 2018, 362, 918.

[97] E. Sage, M. Sansa, S. Fostner, M. Defoort, M. Gély, A. K. Naik, R. Morel, L. Duraffourg, M. L. Roukes, T. Alava, G. Jourdan, E. Colinet, C. Masselon, A. Brenac, S. Hentz. Single-particle mass spectrometry with arrays of frequency-addressed nanomechanical resonators. Nature Communications 2018, 9, 3283. 